\title{
Feeding practices and nutritional status of infants in Morogoro Municipality, Tanzania
}

JOHN G. SAFARI ${ }^{1,3^{*}}$, STELLA C. KIMAMBO ${ }^{2}$ and JAMES E. LWELAMIRA ${ }^{1}$

'Department of Population Studies, Institute of Rural Development Planning, P.O. Box 138, Dodoma, Tanzania

${ }^{2}$ Dodoma Municipal Council, P.O. Box 1989, Dodoma, Tanzania

${ }^{3}$ Sokoine University of Agriculture, Chuo Kikuu, Morogoro, Tanzania

\begin{abstract}
Breast feeding practice especially exclusive breast feeding (EBF) is a major determinant of child growth and development. In Tanzania, most women breastfeed their infants for long periods, but many introduce alternative feeding too early in life. The objective of this study was to determine factors affecting EBF and the relationship between feeding practices and the nutritional status of infants. This crosssectional survey, using a semi-structured questionnaire, was conducted in Morogoro Municipality in Tanzania. The study involved lactating women recruited from five randomly selected health facilities. Demographic, clinical, knowledge and practices related to infant feeding as well as infant anthropometric information were collected. Infant nutritional status was assessed based on weight-for-age, height-for-age and weight- for- height. There were wide variations in knowledge and practice of breastfeeding among women. Majority (92\%) of the respondents gave colostrums to infants although more than $50 \%$ did not know its benefits. Eight percent of the respondents discarded colostrums on the account that it is not good for their neonates. Only $23.1 \%$ of the respondents thought that infants should be breastfed exclusively during the first six months of infancy. Ninety-eight percent of infants $<1$ month of age received breast milk only, compared with $28.5 \%$ of infants aged $2-3$ months and $22.3 \%$ among those who were above 3 months of age. No child in the $\geq 4$ months old was exclusively breastfed. Over $80 \%$ of the infants had normal weights, $13 \%$ were stunted and $8 \%$ wasted. EBF was associated with higher scores for height- for- age $Z(P<0.05)$ and weight- for- height $Z(P<0.01)$. Age, education level and occupation of respondents were important predictors of EBF. Overall, breast feeding practices in the study population were largely suboptimal. As a result, considerable proportions of children had poor health indicators. Thus, correct breastfeeding practices should be supported and promoted to improve the well-being of children.
\end{abstract}

\section{Key words: breastfeeding, practice, infant, nutritional status, Tanzania}

\section{Introduction}

Breastfeeding play a crucial role in child nutrition and development status. Studies have shown that infant weight and height gains during early postnatal life are influenced by infant feeding practices (Picciano et al., 2001). Several guidelines have been developed to promote appropriate infant feeding including the optimal duration of exclusive breastfeeding (EBF). The World Health Organization recommends EBF for the first six months of life (WHO, 2000). This recommendation is based on evidence of the importance of good nutrition in the early months of life and the role it has in achieving good health. The benefits include prevention of disease and infection in childhood (Mihrshah et al., 2003; Hannon et al., 2004) and improved cognitive and motor skills development (Sacker et al., 2006; Kramer et al., 2008).

Breastfeeding practices are determined by various factors including cultural norms, beliefs, mother's knowledge and previous experience (Amal et al., 2007; Nkala \& Msuya, 2011). These factors operate differently across communities and therefore, do affect child health to varying degrees. In Tanzania, 42\% of children are stunted (TDHS, 2010). Stunting in children leads to delay in motor and mental development and increased morbidity and mortality, low physical strength and low economic productivity in adulthood (Grantham-McGregor et al.,

\footnotetext{
*Correspondence jsafari@irdp.ac.tz
} 
1996; Hacker \& Ryan, 2003; Semba, 2008). Nutritional problems of children are to a large extent associated with inappropriate feeding practices (Cernades et al., 2003).

Any breast feeding is beneficial, however, EBF, where the infant only receives breast milk with no additional foods or drinks, has been shown to have short- and long-term benefits for both mother and child (WHO, 2000). Although breast feeding is a norm for most mothers in Tanzania, much remains unclear about the actual practices of infant feeding, their influence on infant nutritional status and the predictors of breast feeding. The objective of this study was to determine the relationship between feeding practices and the nutritional status of infants aged $<6$ months in Morogoro Municipality in Tanzania.

\section{Materials and Methods}

\section{Study area and design}

The study was conducted in Morogoro Municipality in Tanzania. The Municipality is located at latitude $6^{\circ} 49^{\prime} \mathrm{S}$ and longitude $37^{\circ} 40^{\prime} \mathrm{E}$, approximately $200 \mathrm{~km}$ west of Dar es Salaam and about $500 \mathrm{~m}$ above sea level. It has a population of 2,218,492 people of whom $50.7 \%$ are females and $49.3 \%$ are males (NBS, 2013). The study area has a one administrative division with 19 wards and 17 health facilities offering Reproductive Child Health services. Five randomly selected facilities, namely, Uhuru, Sabasaba, Mafiga, Kingulwira and Morogoro Regional Hospital were involved in this study carried out in 2010. Sample size was estimated using the following formula (Amin, 2002):

$$
N=\frac{(Z)^{2} P(1-P)}{\lambda^{2}}
$$

Where $\mathrm{N}=$ sample size; $\mathrm{P}=$ percentage of women attending antenatal clinic whose children were $0-6$

$\lambda=$ maximum error

Since $\mathrm{P}$ was not known for the study population, its value was assumed to be $50 \%$ as it ensures maximum sample size (Nwankwo \& Nwoke, 2009). Further, a maximum error of $10 \%$ and a non- response rate of $30 \%$ were assumed. A sample size of 130 women was obtained. Thus, in each facility, 26 women were randomly selected.

A semi-structured questionnaire was used to obtain information such as demographic characteristics, infant weight and length, health care and infant feeding practices. In addition, two health service providers in each facility were selected for interview. Only children who were biological off springs of mothers attending clinic were included in the measurements.

\section{Anthropometric measurements}

Infants, of both sexes aged 0-6 months, were measured for height $(\mathrm{cm})$ and weight $(\mathrm{kg})$ to assess their nutritional status. Weight was measured on an electronic SECA weighing scale (SECA Vogel and Halke, Haamburg, Germany) that had a digital display. Height was measured with a portable Harpenden stadiometer (Holtain Ltd, London, UK). Readings were made to the nearest $0.1 \mathrm{~cm}$. Adherence to the measuring techniques and recording procedures were observed to reduce measurement error. 


\section{Data analysis}

Data were analyzed for descriptive statistics such as frequencies and percentages using Statistical Package for Social Sciences (SPSS) version 12. Binary Logistic Regression Analysis was used to identify socio-demographic factors that are significantly associated with EBF. In addition, t-tests were used to compare average $z$ - scores on nutritional status indicators between exclusively breastfed and non-exclusively breastfed children. Nutritional status was analysed using Epi- Info statistical package where height for age Z-score (HAZ), weight for age Z-score (WAZ) and weight for height Z- score (WHZ) were used to classify children according to degree of nutritional status.

\section{Ethical consideration}

Ethical approval was obtained from the Sokoine University of Agriculture, Human Studies Ethics Committee. Permission was sought from the Morogoro Region Health authority to conduct the study in the health facilities. Participants were requested for their informed consent to affirm their willingness to participate in the study.

\section{Results}

\section{Characteristics of subjects}

A total of 130 lactating women participated in the study. Most of them (72.3\%) were 21 to 35 years old while $16.2 \%$ were below 20 years. Majority of the women (80\%) in this study had attained primary education and $10 \%$ had secondary school education (Table 1 ). Self employed and civil services constituted over $60 \%$ of the occupation of the respondents. The proportion of women with lower parity (1-2) and higher parity (5-7) was $70.8 \%$ and $10.8 \%$, respectively.

Table 1: Social-demographic characteristics of subjects $(n=130)$

\begin{tabular}{llll}
\hline Category & Response & Frequency & Percent \\
\hline Age of mothers (years) & $<20$ & 21 & 16.2 \\
& $21-35$ & 93 & 72.3 \\
& $>36$ and above & 15 & 11.5 \\
Marital status & Married/living together & 117 & 90.0 \\
& Single/widowed/divorced & 13 & 10.0 \\
Education level & No formal education & 8 & 6.2 \\
& Primary education & 104 & 80 \\
& Secondary & 13 & 10 \\
Occupation & Posts secondary & 5 & 3.8 \\
& Civil servant & 18 & 13.8 \\
& Self-employed & 54 & 42.3 \\
Parity & Housewife/home maker & 49 & 37.7 \\
& Student & 8 & 6.2 \\
& $1-2$ & 92 & 70.8 \\
& $3-4$ & 24 & 18.5 \\
& $5-7$ & 14 & 10.8 \\
\hline
\end{tabular}

Infant feeding practices and breast feeding management

Only $16 \%$ of mothers initiated breastfeeding one hour after delivery. For the majority of subjects (84\%), breastfeeding was initiated 24 hours post delivery. The majority (92\%) of 
women gave colostrums to their infants. However, $50 \%$ of them did not know its benefits (Table 2). Eight percent of the mothers discarded colostrum on the account that it was not good for their neonates. Instead, infants were offered other fluids especially water before mature milk was excreted. Almost all infants (98\%) children were breastfed but $70 \%$ were fed on demand. Sixteen percent of the babies were breastfed 1-2 times a day. Although the health benefits of breastfeeding were acknowledged widely, opinions and practices regarding optimal duration of EBF were divided. Ninety-eight percent of infants under 1 month received breast milk only, compared with $28.5 \%$ of infants aged $2-3$ months and $22.3 \%$ among those who were above 3 months of age. No child in aged above 4 months was exclusively breastfed.

Table 2: Breast feeding management of the respondents

\begin{tabular}{|c|c|c|c|}
\hline Variable & Response & Frequency & Percent \\
\hline \multirow[t]{2}{*}{ Importance of colostrums } & Nutrition and protection & 62 & 47.7 \\
\hline & Do not know & 68 & 52.3 \\
\hline \multirow{6}{*}{$\begin{array}{l}\text { Appropriate time for EBF } \\
\text { (in months) }\end{array}$} & 1 & 5 & 3.8 \\
\hline & 2 & 13 & 10.0 \\
\hline & 3 & 37 & 28.5 \\
\hline & 4 & 29 & 22.3 \\
\hline & 5 & 16 & 12.3 \\
\hline & 6 & 30 & 23.1 \\
\hline \multirow{9}{*}{$\begin{array}{l}\text { Indicator that the baby is } \\
\text { getting enough breast milk } \\
\text { Problems experienced in } \\
\text { breast feeding }\end{array}$} & Weight gain/good health & 92 & 70.8 \\
\hline & Not crying & 38 & 29.2 \\
\hline & Engorgement & 16 & 12.3 \\
\hline & Painful breast & 15 & 11.5 \\
\hline & Cracked nipple & 10 & 7.7 \\
\hline & Mastitis & 5 & 3.8 \\
\hline & Not enough milk & 41 & 31.5 \\
\hline & Breastfeed only one breast & 5 & 3.8 \\
\hline & None & 38 & 29.2 \\
\hline \multirow{5}{*}{$\begin{array}{l}\text { Action taken if a baby is }<4 \\
\text { months and the mother } \\
\text { feels that the baby is not } \\
\text { getting enough breast milk }\end{array}$} & Thin porridge/cow's milk & 79 & 60.8 \\
\hline & Baby formula & 5 & 3.8 \\
\hline & $\begin{array}{l}\text { Increase frequency } \\
\text { breastfeeding }\end{array}$ & 23 & 17.7 \\
\hline & Express breast & 5 & 3.8 \\
\hline & None & 18 & 13.8 \\
\hline
\end{tabular}

\section{Nutritional status of infants}

The majority of infants $(89.7 \%)$ were within the range of normal weights. There was a higher prevalence $(6.1 \%)$ of underweight among female than male infants $(4.2 \%)$ children. Similarly, stunting (height for age $Z$ score $<-2$ ) was more prevalent among females (8.1\%) than males (4.9 $\%)$. The stunting rate of females and males combined was $13 \%$ but only $8 \%$ of children were wasted (weight for height $Z$ score $<-2$ ). The exclusively breastfed children had higher Heightfor- Age Z score $(p<0.05)$ and Weight- for- Height Z score $(p<0.01)$ than children who were not exclusively breastfed (Table 3 ). 
Table: 3. Average scores for Height- for- Age (HAZ), Weight- for- Age (WAZ) and Weight- forHeight (WHZ) for exclusively breastfed and non- exclusively breastfed children

\begin{tabular}{|c|c|c|c|c|c|c|c|c|}
\hline \multirow[t]{2}{*}{ Indicator } & \multicolumn{3}{|c|}{ Exclusively breastfed children } & \multicolumn{3}{|c|}{$\begin{array}{l}\text { Non-exclusively } \\
\text { breastfed children }\end{array}$} & \multirow[t]{2}{*}{ t- value } & \multirow{2}{*}{$\begin{array}{l}\mathrm{P} \text { - } \\
\text { value }\end{array}$} \\
\hline & $N$ & Mean & SD & $N$ & Mean & SD & & \\
\hline $\mathrm{HAZ}$ & 36 & 3.7 & 0.92 & 94 & 3.3 & 0.67 & 2.35 & $<0.05$ \\
\hline WAZ & 36 & 3.9 & 0.87 & 94 & 3.8 & 0.75 & 0.63 & $>0.05$ \\
\hline WHZ & 36 & 4.7 & 0.63 & 94 & 3.8 & 0.59 & 7.5 & $<0.01$ \\
\hline
\end{tabular}

Results of binary logistic regression analysis indicate a significant $(P<0.05)$ association between age, education level and occupation of respondents and exclusive breastfeeding. Women who attained at least secondary education were 1.68 times more likely to practice EBF compared to those with primary or no formal education (Table 4). Women who were selfemployed or not employed/ housewives were four to five times more likely to practice EBF than women with formal employment.

Table 4: Results of Binary Logistic Regression Analysis for reporting EBF (dependent variable) against various socio-demographic variables (independent variables)

\begin{tabular}{|c|c|c|c|c|c|c|}
\hline Predictor & Response & $\beta$ & S.E & $\begin{array}{c}\text { Wald- } \\
\text { Statistic }\end{array}$ & $\begin{array}{l}\text { Odds } \\
\text { ratio } \\
\operatorname{Exp}(\beta)\end{array}$ & $\begin{array}{l}\text { P- } \\
\text { value }\end{array}$ \\
\hline \multirow[t]{2}{*}{ Age of mother } & $<20$ (Ref.) & 0.45 & 0.12 & 14.06 & 1.57 & $<0.05$ \\
\hline & $\begin{array}{l}20-35 \\
\geq 36\end{array}$ & 0.73 & 0.19 & 14.76 & 2.08 & $<0.05$ \\
\hline \multirow[t]{2}{*}{ Marital status } & $\begin{array}{l}\text { Married/living together } \\
\text { (Ref.) }\end{array}$ & & & & & \\
\hline & Single/widowed/divorced & -0.06 & 0.10 & 0.36 & 0.94 & $>0.05$ \\
\hline Educational level & $\begin{array}{l}\text { No formal education } \\
\text { (Ref.) } \\
\text { Secondary and above }\end{array}$ & 0.52 & 0.14 & 13.80 & 1.68 & $<0.05$ \\
\hline \multirow[t]{3}{*}{ Occupation } & $\begin{array}{l}\text { Formal employment } \\
\text { (Ref.) }\end{array}$ & & & & & \\
\hline & Self-employed & 1.34 & 0.45 & 8.87 & 3.82 & $<0.05$ \\
\hline & Others (e.g. housewife) & 1.56 & 0.51 & $9 \cdot 36$ & 4.76 & $<0.05$ \\
\hline \multirow[t]{2}{*}{ Main source of income } & $\begin{array}{l}\text { Salary/self-employed } \\
\text { (Ref.) }\end{array}$ & & & & & \\
\hline & Husband support & 0.24 & 0.94 & 0.07 & 1.27 & $>0.05$ \\
\hline Parity & $\begin{array}{l}1-2 \text { (Ref.) } \\
\text { More than } 2\end{array}$ & 0.22 & 0.79 & 0.08 & 1.25 & $>0.05$ \\
\hline
\end{tabular}




\section{Discussion}

Findings in this study show that socio-demographic characteristics of mothers have significant influence on feeding practices. The low level of women's education as observed in the present study has potential negative and indirect effects on child nutrition, feeding patterns and overall improvement of the socio-economic conditions (Huq \& Tasnim, 2008). Low level of education is also associated with indirect effects on the understanding of nutrition and food aspects as well as improvement of socio-economic conditions (Mosha \& Philemon, 2010). The Tanzania Health Survey (TDHS, 2010) report showed the likelihood of children being fed appropriately increases with mother's education. However, mothers who were formally employed indicated that both the frequency and duration of breastfeeding were affected as work conditions were not always conducive for optimal breast feeding. In Malta, Montalto et al. (2010) observed a general lack of support for breast feeding in the workplace, and many women stopped breast feeding. Supportive environment for breast feeding has been described as a critical determinant for successful breast feeding after 3 months or longer (Meek, 2001).

Breastfeeding initiation, the start of breastfeeding within one hour after delivery (WHO, 2000), was practiced by a small proportion of women. Delayed initiation deprives infants of the immunological and nutritional benefits of colostrum, and is likely to increase risks of neonatal mortality or impede optimal nutritional status (Edmond et al., 2006). Colostrum is particularly rich in immunoglobulins, antimicrobial peptides, and other bioactive molecules, including growth factors. It is important for the nutrition, growth and development of infants and confers immunologic defence to neonates (Playford et al., 2000; Lawrence \& Pane, 2007). Breastfeeding for the first six months of infants' lives has been found to be a cost effective intervention in saving children's lives and can avert $13-15 \%$ of the 9 million deaths of children under 5 years old in low and middle income countries (Jones et al., 2003). Our study shows that prevalence of EBF is below the national average of $50 \%$ (TDHS, 2010) and the prevalence of $36 \%$ in low income countries (WHO, 2009).

The suboptimal breast feeding practices in terms of frequency and duration observed for most infants is not uncommon in Tanzania. For instance, as low as $19 \%$ prevalence of EBF was found in Mbeya (Poggensee et al., 2004) whilst in Morogoro, EBF was reported as rare and of short duration (Shirima et al., 2000). These low rates of EBF are nonetheless not limited to Tanzania alone. Coutsoudis et al. (2001), in a prospective study in South Africa, reported a median duration of EBF of three weeks and a probability of $29 \%$ of finding women breastfeeding at three months.

The low prevalence of EBF means early introduction of breast milk substitutes such as formula and other kinds of milk to infants. Often, milk substitutes provide too few calories andexpose the infants to the risk of infection (Imdad et al., 2011).A meta-analysis from three developing countries showed that infants who were not breastfed had a six-fold greater risk of dying from infectious diseases within the first two months of life than those who were breastfed (WHO, 2000).

Nutritional status of children on the basis of weight-for-age (indicator of underweight), height-for-age (indicator of stunting) and weight-for-height (indicator of wasting) show considerable variations when compared with the national averages of nutritional status of children of similar ages. The present study demonstrates that $10.3 \%$ of children are underweight. This proportion is higher than the national average (8.7 \%)for age $<6$ months(TDHS, 2010).Such variations could be due to differences in infant feeding practices and the many factors influencing child care including education, attitude towards EBF, 
knowledge about good breast feeding practices and cultural differences. Moreover, the sample sizes were different. The observed proportion of stunting children in our study (13\%) is lower than the national average (18.3\%) for children in the age <6 months (TDHS, 2010). Stunting is a common problem in Tanzania (Matee et al., 1997; Mamiro et al., 2005; Leah, 2007; Clemens \& Demombynes, 2012), and may have serious implications. It is worth noting that children deprived of nutrients for healthy growth are also deprived of nutrients for healthy brain development and healthy immune system (Amsalu \&Tigabu, 2008).

The proportion of wasted children in the present study is higher than the national average $(6.4 \%)$ for children of similar age ( $<6$ months) in Tanzania (TDHS, 2010). Wasting represents a more accurate reflection of current period of sickness and short term food shortage that led to significant weight loss; it also indicates deficit in tissue and fat mass compared with amount expected in a child of the same height or length and may result either from failure to gain weight or from actual weight loss (WHO, 2000). It is intriguing to note that non-exclusively breast fed children have had significantly lower scores of HAZ and WHZ than their counterparts. The findings are consistent with those from other studies (Kikafunda et al., 1998; Playford et al., 2000; Saha et al., 2008; Amsalu \& Tigabu, 2008) which show that inappropriate feeding practices can have profound consequences for the growth, development, and survival of children. Studies from Bangladesh and Brazil have shown that breastfed children, who were given additional food during the first six months of life, had two to threefold higher mortality from diarrhoea and pneumonia than infants who were exclusively breastfed (Black \& Victora, 2002; Saha et al., 2008). In contrast, a positive association between EBF and health status of the children has been documented (Smith \&Haddad, 2000; Sheehan et al., 2001). Thus, for the children to grow well, EBF needs to be supported and its importance communicated to prospective mothers taking into account, the predictors of EBF.

Specific individual differences in attitudes, beliefs and experience are known to influence the decision to breast feeding practices and therefore, as indicated in this study, predictors of EBF vary widely. Findings from other studies show that having higher years of education, giving birth at older age, having had previous pregnancies and living with a partner are associated with increased likelihood of six-month EBF (Dubois \& Girard, 2003; Millar \& Maclean, 2005; Semenic et al., 2008; Al-Sahab et al., 2010). Thus, it is plausible that background characteristics of mothers constitute the basis for designing interventions that aim to improve the breastfeeding practices in a particular area. A major limitation of this study is that the sample size was small and therefore, the findings cannot be generalized.

In conclusion, breast feeding practices in the study population were largely suboptimal. As a result, considerable proportions of children had poor health indicators. Thus, correct breastfeeding practices should be supported and promoted since proper nutrition during infancy is essential for attaining and maintaining good health. Because standards explicitly identify EBF as the normative mode for growth and development and survival of infants, accurate information on the importance of early initiation of breastfeeding andsix months of EBF would be particularly important.

\section{References}

Al-Sahab, B., Lanes, A., Feldman, M. \& Tamim, H. (2010) Prevalence and predictors of 6-month exclusive breastfeeding among Canadian women: a national survey. BMC Pediatrics8, 10:20 
Amin, M.E. (2002). Foundations of Statistical Inference for Social Science Research. Makerere University Press, Kampala, pp: 338.

Amal, O.,Lars-Åke, P. \& Pia, O. (2007) Whom can I rely on? Mothers' approaches to support for feeding: An interview study in suburban Dar es Salaam, Tanzania. Midwifery 23, 172-183

Amsalu, S.\& Tigabu, Z. (2008) Risk factors for severe acute malnutrition in children under the age of five: A case-control study. Ethiopian Journal of Health and Development 1, 21-25.

Black, R.E.\& Victora, C.G. (2002) Optimal duration of exclusive breastfeeding in low income countries. British Medical Journal 325, 1252-1253.

Cernades, J.M., Nocada, G. \& Barrera, L. (2003) Maternal and perinatal factors influencing the duration of exclusive breastfeeding during the first 6 months of life.Journal of Human Lactation 19, 136-144.

Clemens, M.\& Demombynes, G. (2012) Multisector intervention to accelerate reductions in child stunting: an independent critique of scientific method. American Journal of Clinical Nutrition95, 774-775.

Coutsoudis, A., Pillay, K. \& Kuhn, L. (2001) Method of feeding and transmission of HIV-1 from mothers to children by 15 months of age: prospective cohort study from Durban, South Africa. AIDS 15, 379-387.

Dubois, L.\& Girard, M. (2003) Social determinants of initiation, duration and exclusivity of breastfeeding at the population level: The results of the longitudinal study of child development in Quebec (ELDEQ 1998-2002). Canadian Journal of Public Health 94, 300-305.

Edmond, K.M., Zandoh, C., Quigley, M.A., Amenga-Etego, S., Owusu-Agyei, S. \& Kirkwood, B. (2006) Delayed breastfeeding initiation increases risk of neonatal mortality. American Academy of Pediatrics 117, 380-386.

Grantham-McGregor, S.M., Walker, S.P. Himes, J.H.\& Powell, C.A. (1996) Stunting and mental development in children. Nutrition Research 16, 1821-1828. Hacker, A \& Cass, R.C. (2003) Prevalence of infant stunting in an urban Kenyan population: comparison to the 1998 Kenyan Health and Demographic Survey and the 2000 CDC growth grids. Nutrition Research 23, 1643-1649.

Hannon, P.R., Willis, S.K. \& Bishop-Townsend, V. (2000) Adolescent mothers' infants feeding decisions and breastfeeding practices; a qualitative study. Journal of Adolescent Health 26, 399-409.

Huq, M.N \& Tasnim, T. (2008)Maternal education and child healthcare in Bangladesh, Maternaland Child Health Journal 12,43-51.

Imdad, A, Yakoob, M.Y.\& Bhutta, Z.A. (2011) Impact of maternal education about complementary feeding and provision of complementary foods on child growth in developing countries, BMC Public Health 11(Suppl 3):S25

Jones, G., Steketee, R.W., Black, R.E, Bhutta, Z.A\& Morris, S.S. (2003) Bellagio Child Survival Study Group. How many child deaths can we prevent this year? Lancet 362, 65-71.

Kikafunda, J.K., Walker, A.F., Collet, D \& Tumwine, J. (2012) Risk factors for early childhood malnutrition in Uganda. Pediatrics 102,e45

Kramer, M.S., Fombonne, E., Igumnov, S., Vanilovich, I., Matush, L., Mironova, E., Bogdanovich, N., Tremblay, R.E., Chalmers, B., Zhang, X. \& Platt, R.W. (2008) Effects of prolonged and exclusive breastfeeding on child behavior and maternal adjustment: evidence from a large, randomized trial. Pediatrics 121, 435 - 440.

Lawrence, R.M.\& Pane, C.A. (2007) Human breast milk: current concepts of immunology and infectious diseases. Current Problems in Pediatrics and Adolescent Health Care 37, 7.

Leah, V. (2007) Children and vulnerability in Tanzania: A Brief Synthesis. Special Paper 07.25, Dar es Salaam, Research on Poverty Alleviation. 
Mamiro, P.S., Kolsteren, P., Roberfroid, D., Tatala S., Opsomer, A.S. \& Van Camp, J.H. (2005) Feeding practices and factors contributing to wasting, stunting, and iron-deficiency anaemia among 3-23-month old children in Kilosa district, rural Tanzania. Journal of Health Population and Nutrition 23, 222-230.

Matee, M.I., Msengi, A.E., Simon, E., Lyamuya, E.F., Mwinula, J.H., Mbena, E.C.,Samaranayake L.P. \&Scheutz, F. (1997) Nutritional status of under fives attending maternal and child health clinics in Dar es Salaam, Tanzania. East African Medical Journal 74, 368-371.

Meek, J.Y. (2001) Breastfeeding in the work place. Pediatric Clinics of North America 48, 461-474

Mihrshahi, S., Ichikawa, N., Shuaib, M., Oddy, W., Ampon, R., Dibley, M.J. \&Kabir, A.K.M.I. (2003)

Prevalence of exclusive breastfeeding in Bangladesh and its association with diarrhoea and acute respiratory infection: results of the Multiple Indicator Cluster Survey 2003. Journal of Health Population and Nutrition 25, 195-204.

Millar, W.J.\& Maclean, H. (2005) Breastfeeding practices. Health Reports 16, 23-31.

Montalto, S.A., Borg, H., Buttigieg-Said, M\&Clemmer, E.J. (2010) Midwifery26, e6-e13.

Mosha, T.C.E.\&Philemon, N. (2010) Factors influencing pregnancy outcomes in Morogoro Municipality, Tanzania. Tanzania Journal of Health Research 12, 249-259.

NBS (2005).Tanzania Demographic and Health Survey 2004-05: Key Findings. National Bureau of Statistics (Tanzania) and ORC Macro, Calverton, Maryland, USA.

NBS (2013).Population and Housing Census. National Bureau of Statistics (Tanzania).

Nkala, T.E. \& Msuya, S.E. (2011) Prevalence and predictors of exclusive breastfeeding among women in Kigoma region, Western Tanzania: a community based cross-sectional study. International Breastfeeding Journal 6, 17.

Nwankwo, B.O\&. Nwoke, E.A. (2009) Risky sexual behaviour among adolescents in Oweri Municipal:Predictors of unment family health needs. African Journal of Reproductive Health 13, 135-145.

Picciano, M.F. (2001). The evidence of breastfeeding: nutrient composition of human milk. Pediatric Clinics of North America 48, 53-67.

Playford, R.J., Macdonald, C.E. \& Johnson, W.S. (2000) Colostrum and milk-derived peptide growth factors for the treatment of gastrointestinal disorders. American Journal of Clinical Nutrition 72,5 .

Poggensee, G., Schulze, K., Moneta, I.,Mbezi, P.,Baryomunsi, C \& Harms, G. (2004) Infant feeding practices in western Tanzania and Uganda: implications for infant feeding recommendations for HIV-infected mothers. Tropical Medicine and International Health9, 477-485.

Sacker, A., Quigley, M.A.\& Kelly, Y.J. (2006) Breastfeeding and developmental delay: findings from the millennium cohort study. Pediatrics 118, 682-689.

Saha, K., Frongillo, E.A., Alam, D.S., Arifeen, S.E., Persson, L.A.\& Rasmussen, K. (2008) Appropriate infant feeding practices result in better growth of infants and young children in rural Bangladesh. American Journal of Clinical Nutrition 87, 1852-1859.

Semba, R.D. (2008) Effect of parental education on child stunting. Lancet 171(9627), 1837.

Semenic, S., Loiselle, C.\& Gottlie, L. (2008) Predictors of the duration of exclusive breastfeeding among first-time mothers. Research in Nursing \& Health 31, 428-441.

Sheehan, D., Krueger, P.\& Watt, S. (2001)The Ontario Mother and Infant Survey: breastfeeding outcome. Journal of Human Lactation 17, 211-219.

Shirima, R., Greiner, T., Kylberg, E. \& Gebre-Medhin, M. (2000) Exclusive breast-feeding is rarely practised in rural and urban. Public Health Nutrition 4, 147-154.

Smith, L.C.\& Haddad, L. (2000)Explaining child malnutrition in developing countries. A crosscountry analysis. International Food Policy Research Institute. Research Report 111. 
TDHS(2010) Tanzania Demographic and Health Survey. Preliminary Report. National Bureau of Statistics, United Republic of Tanzania, Measure ICF Macro., USA

WHO (2000) Collaborative Study Team on the Role of Breastfeeding on the Prevention of Infant Mortality: Effect of breastfeeding on infant and child mortality due to infectious diseases in less developed countries: a pooled analysis, Lancet 355, 451-455.

WHO (2009) Infant and young child feeding: Model Chapter for textbooks for medical students and allied health professionals. Geneva. 